\title{
Profile: The Living Archives Project: Canadian Disability and Eugenics
}

\author{
Colette Leung, University of Alberta
}

\section{cs11@ualberta.ca}

\begin{abstract}
Between 1928 and 1972, a unique chapter in the history of eugenics developed in Western Canada, directly affecting a number of individuals believed to be "defective," resulting in their sterilization and institutionalization under legislative law. These individuals included many marginalized groups, but the vast majority of those targeted had developmental disabilities. The history of eugenics in Western Canada, therefore, is an important legacy of disability studies. The Community-University Research Alliance (CURA) project, Living Archives on Eugenics in Western Canada joins some 30 research scholars and sterilization survivors, and 12 community partners across Western Canada, in order to engage communities in developing accessible resources to investigate and create awareness surrounding the history of eugenics in Canada, including its social and political contexts. These resources include interviews and narrative videos with individuals directly affected by eugenic practices, now mostly in their $60 \mathrm{~s}$ and $70 \mathrm{~s}$. The project also seeks to explore the relationship between this history and current practices, especially in biomedicine. Examining this current project can help create precedent and resources for research in disability studies, with emphasis on inclusivity during research and the creation of accessible resources. The Living Archives project is an example of Canadian perspective on a unique history, rarely studied, but integral to disability studies.
\end{abstract}

Keywords: Eugenics; Disability; Western Canada; Disability Research; History of Eugenics; Living Archives; Vulnerable Populations 


\section{Profile: The Living Archives Project: Canadian Disability and Eugenics}

\section{Definitions of Eugenics}

The long popular desire to "improve" the human race found its footing in the early $20^{\text {th }}$ century through the eugenics movement, ideas and practices of North America. Eugenics was an embraced science and way of thinking. These practices however, created long lasting consequences, and a chapter of history generally overlooked in North America. Most typically, eugenics is associated with Nazi Germany, where the basis for eugenics was founded in the concept of the Aryan race (Grekul et al, 2004, p.358). However, the eugenics movement held an active legacy throughout the world, in Scandinavian and American contexts (Wilson, 2010, p.3), and left large impacts on technology, human variation, and community.

The term "eugenics" was coined by Francis Galton (1883), and explained as "the science of improving stock... which, especially in the case of man, takes cognizance of all influences that tend in however remote a degree to give to the more suitable races or strains of blood a better chance of prevailing speedily over the less suitable" (p. 19). The Oxford English Dictionary provides a succinct definition: "pertaining or adapted to the production of fine offspring, esp. in the human race." It was believed that "negative" traits were heritable through genetic descendants in the human race; similar concepts were applied in the breeding of farm animals, which were bred to create stronger and more robust animals through selective breeding (Grekul et al, 2004, p.362). Eugenics implied that human beings could be "improved" in similar fashion. 
Eugenics therefore covers a broad spectrum of employable methods, including but not limited to: institutionalization, which separates individuals from society so they are no longer part of it; the encouragement of reproduction of certain individuals with traits believed to be better than others; and physical sterilization of individuals to prevent them from ever having children. This popular method of thinking was believed to improve the human race - an idealistic goal with dismaying consequences.

Individuals targeted for eugenics were often marginalized groups - single mothers, immigrants, and people of lower social economic class (Grekul et al, 2004, p. 358). But, the most central target group of eugenic practices were people with a variety of disabilities, both mental and most notably, developmental, (Wendel-Hummell et al, 2009, p. 1) who were feared and perceived as being "out of control" or "vulnerable to seduction" (Savell, 2004, p. 1093). In order to understand eugenics, one must also understand and question disability, because of the targeting of the specific population of disabled people. Canada was not exempt of eugenic practices, and in Western Canada, eugenics was a powerful player in political and social spheres. However, this chapter in both Canadian history and the history of eugenics, remains largely disregarded (Wilson, 2010, p.2-3), despite its impacts on individuals and the legacy and context its effects have left to Canadian disability studies.

This paper will examine the role of eugenics in Canadian disability studies, through the overview of the project Living Archives on Eugenics in Western Canada, a project, which seeks to create an oral history and a collective memory of individuals impacted by eugenic practices in Western Canada. A brief history of the role of eugenics in Western Canada is provided, and an explanation of the Canadian Living Archives 
project structure, alongside its views, methods, and approaches to the field. This will be used to demonstrate the unique Canadian history disability studies has through the relationship of eugenics and disability, including the recognition of some of the key works for disability studies, and the need for such a project to be conducted in current times, while primary information from sterilization survivors is still available. Some discussion is also held for the future directions of study the Living Archives project might inspire. The Living Archives is a project that provides a vital part of Canadian history to disability studies that is often overlooked, but is unique and of value to both researchers and community members through its methodology and content.

\section{Canada and Eugenics}

The eugenics movement was no stranger to Canada, and most especially to Western Canada, where a largely rural population resided. The leap from selective breeding in their own animal stocks to eugenics was easily made, and Alberta would become the leader of the eugenics movement in Canada, as the province in which the vast majority of eugenic sterilizations were performed.

Alberta was the first province to introduce the Sexual Sterilization Act in 1928, a law largely supported by figures such as Emily Murphy and Nellie McClung, "prominent first-wave feminists,'(Mansell, 1998, p.4) who in 1927, along with three other women: Henrietta Muir Edwards, Louise McKinney, and Irene Parlby, won the "Person Case" as the "Famous Five" allowing for women to be recognized as legal persons, and able to sit in the Senate (Dodd, 2009, p.41). This placed Alberta among a number of other North American jurisdictions, including Indiana (1907), California (1909), and eventually 
British Columbia (1933) (Wilson, 2010, p.3). A number of other states implemented eugenic practices through the segregation of individuals, without the official Sterilization Act witnessed in the previously listed provinces (Grekul et al, 2004; Selden, 2000; Wilson, 2010). Western Canada is further made unique in Canada, for other major provinces such as Ontario were afraid to follow in Alberta's footsteps and openly embrace eugenic sterilization laws "fearing the wrath of Roman Catholic voters" (Fitzgerald, 2010, p.301). However, in Alberta alone, some 4739 residents were recommended for sterilization (Grekul et al, 2004, p. 358).

The Sexual Sterilization Act allowed for the surgical sterilization of "mental defectives," promoting a healthy populace while reducing cost of these individuals on the state. These "mental defectives," included individuals officially classified as "imbeciles," defined as those who are usually "physically defective"; and "morons," those were the "most dangerous," for they "pass as normal individuals and more is expected of them than their capabilities permit." (Fisher, 2010, Slide 1) Individuals were often also placed within institutions. Grounds for sterilization therefore applied to both those with physical and mental conditions, all of which were believed to be heritable; and on the grounds that these individuals would not make suitable parents (Grekul, 2008, p.247). Individuals with disabilities, especially developmental disabilities, were not the only ones targeted - single mothers, Aboriginal people, eastern Europeans, and poor people were all subjected to eugenic practices (Grekul et al, 2004, p. 358). This Act was an example of explicit eugenics. Most North American jurisdictions, however, began to wane in the implementation of their eugenic practices following the Second World War, and the role the Nazis played in eugenics. However, Alberta's sterilization program, and 
its embrace of eugenics, continued until 1972, because of "a unique set of social, political, and economic circumstances in the province" (Grekul et al, 2004, p. 358), and in British Columbia until 1973, when the Acts were repealed.

It was not until 1996 that a sterilization survivor, who had not even been informed of her surgical sterilization as a teenager until she attempted to have children as an adult, drew public attention to Alberta's history of eugenics. Leilani Muir, a team member of the Living Archives on Eugenics in Western Canada, took legal action against the Province of Alberta, and won a landmark legal case in 1996 for wrongful sterilization and confinement. This incident helped contribute to preserving a rich documentary basis for understanding the history of eugenics in Western Canada, but also to bring eugenics under the public eye again. The National Film Board created a documentary after the case, known as The Sterilization of Leilani Muir, and the success of Leilani Muir's legal action instigated the launch of more than 900 legal action cases against the Province for wrongful sterilization and confinement, most of which were settled by the Province out of court (Grekul et al, 2004, p. 364).

However, an understanding of eugenics, and why it met with such success as it did in Western Canada is important for many reasons to disability studies, and to all Canadians who embrace diversity. Contemporary practices surrounding disability, such as the screening for Trisomy 21 (Down Syndrome) or the abortion of "defective fetuses" is a contemporary form of eugenics, known as "newgenics" (Rembis, 2009, p.585) with “serious potential consequences for human variance and diversity." (Wiener et al, 2009, p. 599). These medical practices are meant to help discover the genetic causes of disability, but "could not only further stigmatize disabled people, but essentially, target 
them for elimination." (Childress, 2003, p. 157) Examining the history of eugenics and its relationship to disability should raise questions around the "idea that 'health' equates with physical perfection." (Childress, 2003, p.157) Understanding the past of eugenics helps us make informed decisions in present-day situations, and to understand the beauty of diversity. Further, the history of eugenics in Western Canada is unique compared to other chapters in global context.

The Living Archives on Eugenics in Western Canada project, which is formed by an alliance of Western Canadian universities and community partners seeks to study this history, providing a legacy to disability studies often unexplored. Further, this project is a Canadian one, and lends Canadian perspective to disability and eugenics, as well as unique methods, resources and approaches to the field. In order to better understand these, an overview of the Living Archives is instructive.

\section{The Living Archives Project}

The Living Archives Project is funded by the Community-University Research Alliance (CURA) Program, as well as by the Social Sciences and Humanities Research Council of Canada (SSHRC). It is projected as a five-year project, currently entering its second year. The project aims to explore eugenics and related concepts that are meant to "improve" humans through selective reproduction using a number of different methods, most especially in Western Canada, which is largely under-studied and outside of public awareness. As a CURA Project, the Living Archives involves some 30 research scholars and sterilization survivors from Western Canada, and 12 community partners. Universities that have been involved in the project include the University of Alberta, the 
University of Calgary, the University of Saskatchewan, the University of Lethbridge, and consultation among many other academics. The aim of Living Archives on Eugenics in Western Canada is to create awareness of eugenics, and of its Canadian legacy (Wilson, 2010, p.2-3). Such a legacy includes past social practices and policies, and current issues that were central to the eugenics movement, including reproductive freedom, institutionalization, and the "sorts of people" that should be in future generations.

The Living Archives hopes that such education will be accomplished through the creation and implementation of a number of academic and public resources, including: research; academic papers; a public website; curriculum development; video narratives; in-person information through the form of conferences and public dialogue; and public work such as plays and art (Wilson, 2010, p.7). All of these goals will be met through the integration of traditional archival work with community organizations, exemplifying the value of inclusiveness at the heart of the project.

However, the Living Archives on Eugenics in Western Canada is a project that looks at eugenics in a way rarely explored by examining eugenics, for few "have considered the relative status of various disability populations as targets of eugenic control" (O’Brien \& Bundy, 2009, p. 153); but the relationship between eugenics and disability truly comes to the forefront in this project. "Central amongst those targeted by such eugenic practices were people with a variety of disabilities, especially (but not only) developmental disabilities" (Wilson, 2010, p.2). In Western Canada, eugenics was bound to disability, and so the Living Archives on Eugenics in Western Canada is not only a eugenic examination, but in context of its Canadian focus, a disability studies project. Research on the history of eugenics provides a rarely discussed history and 
lasting context to Canadian disability studies itself, as well as providing important modern research to the field.

\section{What Sorts of People Should There Be?}

The project, Living Archives on Eugenics in Western Canada, was first outlined through the What Sorts Network. The What Sorts Network is short for "What Sorts of People Should There Be?" and is an international network of over 60 researchers and community members, who interact on their research and projects, in order to examine the question, "What Sorts of People Should There Be?" (http://whatsorts.net/). The Network states on their website that "Much of the work that we support and are interested in undertaking is focused on understanding the nature of human diversity and variation, our ability to influence this variation, and what this means for how we live together in the world." The Network strives to create debate and inform social policy that crosses over the humanities, biomedical technologies, and the social science, with the goal of creating inclusive communities. The Coordinator of What Sorts, Dr. Rob Wilson, is also the Project Lead of the Living Archives project.

The conception for the Living Archives on Eugenics in Western Canada project began some 18 months before CURA funding was obtained, and many of the same issues arising from discussion on the What Sorts network created the framework for the Living Archives on Eugenics in Western Canada project.

\section{Project Structure}


The Living Archives on Eugenics in Western Canada project has several objectives.

These include enhancing archival collections, and improving their accessibility to researchers from fields including history, sociology, philosophy, medicine, law, and education; recording oral histories of sterilization survivors, their family, and others at a time when it is crucial to gather this information before it is lost and left out of Canadian history; creating a public, interactive website; as well as providing in-person information through curriculum bundling, public dialogues and conferences on relevant issues (Wilson, 2010, p.7). Many of the organizations involved with the Living Archives are major developmental disability and self-advocacy organizations; truly linking the Living Archives with disability research through inclusivity.

In order for the Living Archives to cover these goals, the project is divided into a team structure. The project director is Rob Wilson (FRSC) of the University of Alberta, an accomplished team builder with a strong history of starting, organizing, and managing interdisciplinary projects. Professor Wilson leads the leadership team, including several interdisciplinary academic and community co-applicants. Dr. Wilson also currently directs Philosophy for Children Alberta (www.ualberta.ca/ phil4c/) and is the founder of the What Sorts Network (http://whatsorts.net/).

Academic team leaders include Dr. Erika Dyke of the University of Saskatchewan; Dr. Dick Sobsey of the University of Alberta; and Dr. Gregor Wolbring of the University of Calgary. Community leaders include Nicola Fairbrother, the Director of Neighborhood Bridges; and Bruce Uditsky, the Chief Executive Officer for the Alberta Association for Community Living. Also joining team leaders as Technical Lead is Natasha Nunn, of Silversky Solutions based in Edmonton, Alberta. An additional 23 
members create the remainder of the research team, supplemented by graduate and undergraduate students.

Teams are divided into five major themes to be explored relating to eugenics and disability.

Traditional Archives + is led by Dr. Erika Dyck, a historian with research interests in the history of Canadian psychiatry, mental health, and medical experimentation. The Traditional Archives + team conducts traditional academic research using paper-based archives on the history of eugenics, including but not limited to records pertaining the sterilization of survivors, and institutional records. The Traditional Archives + team looks also to improve the quality of available archival records, and to increase accessibility to these materials. Currently, the team is examining ways to help instruct researchers on how to apply for access records under the Freedom of Information and Protection of Privacy (FOIP) Act of Alberta, for example.

Reproductive Choice in an Ableist World is a team led by Nicola Fairbrother. This team seeks to develop inclusive collective memories surrounding eugenics in Western Canada, and the effects eugenics has had on modern society. The Reproductive Choice team examines cases where the ability of individuals to bear children was limited or affected by outside influence, and will deliver video narrative of survivors and other relevant individuals stories. Community involvement through this team will also be accomplished through input in curriculum materials.

The Parenting with Disability team is led by Bruce Uditsky, of the Alberta Association for Community Living. This team also seeks to record individual narratives, but also to promote public dialogue on eugenics, inclusion, and social policies that affect 
people with disabilities. These community discussions may touch base on ethical issues as well, and are meant to access the public through a number of different mediums, including conferences, seminars, etc. These ethical issues include inspiring the public to ask questions surrounding not only what technologies and courses of action could be applied towards "improving" humans; but also what should be used.

The Post-Eugenic Futures team is led by Dr. Gregor Wolbring of the University of Calgary. The core activities of Post-Eugenic Futures surround increasing public participation through viral archiving mechanisms, as well as small-scale workshops and community-based activities. In addition, the Post-Eugenic Futures team will explore issues where disability, technology, reproduction and human enhancement overlap; most especially in using foresight analysis to gauge issues of the future.

Finally, the Technical Team is led by Natasha Nunn of Silversky Solutions. The Technical Team is involved in facilitating project management, including digital storage of records and project co-ordination; and in constructing a digital platform in the form of a website for research and public outreach. Currently, plans are in development to create a public website, including a back-end repository of archival materials, as well as reappropriate primary source materials in order to create an interactive and engaging website aimed at students and the general public. The digital platform will cover issues that the Living Archives project is meant to explore, from both historical and present-day views. Further, the Technical Team is committed to delivering a platform that is accessible to an audience including those individuals with disabilities.

Through these five teams, the Living Archives project hopes to explore historical contexts of eugenics and disability by examining traditional archives and recording 
individual narratives of affected parties. The project will also explore social and cultural contexts of Western Canada and the social conditions that resulted in the forms eugenics took in the early $20^{\text {th }}$ century, as well as the effect this has had on technology and modern society. Political contexts will be examined through the development of statutes and acts to enforce sterilization, and to a certain degree, the steps involved in exploring this delicate subject as a researcher.

In additional to the aforementioned teams, the Living Archives project has formed a number of partnerships with community associations. The number of partners at the outset of the project was 12 , although it is hoped that this number will grow as the project develops. These community partners and the role they will play in the Living Archives project are outlined as follows.

Field Law is a community partner who is involved in safeguarding important historical documents; as well as with providing legal advice on how to move documents created by the project into trusted and existing archival repositories.

The Alberta Association for Community Living seeks to help professionals, parents and children with developmental disabilities affected by eugenic practices to become involved with the development of curricular programs, workshops, and training for students, and community networks that the project will develop.

In order to create inclusive discussions of disability and surrounding issues such as the ethics, philosophy, and legal frameworks of being an individual and a person, the Canadian Association for Community Living provides leadership on a national level and aids the Alberta Association for Community Living in linking past, present, and future issues of eugenics and disability. 
Neighborhood Bridges is a community partner who specializes in connecting with volunteers who have lived in institutions and/or have been sterilized, providing them with a safe space for discussions that are usually sensitive and painful for individuals. This community partner also works with traditional disability organizations, and promotes dialogue in the community at large. The team leader, Nicola Fairbridge, comes from this community partner.

One of the major goals of the Living Archives project is to develop material that can be used within school curriculums. To this end, the Public School Boards' Association of Alberta will be involved with dialogue with school superintendents and public school boards. This community partner is also key in advocating to government and public community for fully inclusive and rounded education, and the recognition of human rights.

The leading independent literary press of Western Canada, NeWest Press will increase promotion of the Living Archives project to both a North American and overseas audience, providing a global context for the research created through the project.

The Maa and Paa Theatre is a small theatre group interested in bringing Western Canadian history to the stage. The theatre group will develop theatric works for public audiences. Already, the Living Archives has been able to celebrate the creation of many artistic representations including art and theatre, inspired by the research conducted by the project.

SilverSky Solutions is the community-focused, local web-development company the team lead Natasha Nunn is part of. This community partner offers expertise in 
technology, in order to help create interactive and innovative online user-experiences that will also promote accessibility.

The Edmonton Public Library is also involved in the project, as a community partner that will continue to offer the public free and open access to written materials, computer labs, and meeting spaces for public events.

The American Association of People with Disabilities offers to ease communication with other countries, and the dissemination of project deliverables within North America. This community partner may also help ground the Living Archives project in the broader context of North America.

Many government records of great value to the Living Archives, as well as private archival records including important components of Alberta's history are found in the Provincial Archives of Alberta. This community partner will help access these archival materials, and also aid the integration new archival materials created by the project.

Finally, the Legal Archives Society of Alberta is a non-profit organization that will provide advice on legal archiving in Alberta, and provide consultation for relevant legal documentation to the project, both in accessing and using archival records.

The involvement of community partners is a large benefit of the CURA funded Living Archives project, and a significant boost to the methodology of disability studies itself. The enrichment of community involvement not only allows for a more complete project, but also adds several layers to the outcomes of the Living Archives project, and for potential future research conducted in Canadian disability studies.

\section{Future Project Outcomes}


A number of concrete deliverables are expected to come out of the Living Archives project. The most obvious of these is perhaps the development of an interactive, comprehensive and multi-layered website, aimed for both public use and for conducting research into the history of eugenics in Western Canada. This website also aims to be accessible to an audience including individuals with disabilities. As well, a number of new archival materials are currently being generated in the form of web-cam narratives that are recorded interviews with individuals impacted by eugenics in any number of ways, whether they are sterilization survivors, family members, lawyers, etc. Naturally, the Living Archives project will also produce a number of standard academic works on the history of eugenics, including articles and monograms.

However, the Living Archives project also aims to create high school and university curriculum units - many of these are already under way, focusing on eugenics and sterilization in Western Canada, including institutionalization and specific communities affected by eugenics such as those with disabilities, women, and Native Americans. In conjunction with this, the Living Archives project will also reach a large public audience through the organization and creation of public dialogues, workshops, and conferences.

A final deliverable includes the establishment of a concrete protocol including ethical criteria for recording oral histories of vulnerable individual community members. This protocol can hopefully be applied in a number of other disciplines, including that of disability studies.

Already, the impacts of eugenics are being recognized on a more public scale: the 2011 Edmonton Fringe Festival showcased two plays sponsored by the What Sorts 
Network, and the Living Archives project. These plays are entitled "The Book of Jobes," and "Aleugentia" (What Sorts, 2011). Further, the project has helped sponsor the showcasing of local art relating to eugenic themes.

Perhaps most notably, the Mayor of Edmonton, Alberta, Stephen Mandel proclaimed October 23, 2010 as Remembering the History of Eugenics in Alberta Day (Workman, 2010).

However, outside of these projected deliverables from the Living Archives on Eugenics in Western Canada, the project itself is significant for its inclusion of community partners. The history of eugenics is steeped with principles of exclusionpreventing vulnerable individuals from fully participating in society through institutionalization, family and community segregation, and sterilization. The project deals with the experiences of sterilization survivors, and could easily treat sterilization survivors as tools through which to gather knowledge, and through that path would fall into the error of exclusion. The Living Archives though is invested in involving vulnerable individuals, and community organizations with academic researchers themselves, in order to improve inclusivity, and to build resources together that portray an accurate history of eugenics and sexual sterilization in Western Canada. The involvement and inclusion of community partnerships in the Living Archives project makes this a work that involves vulnerable peoples on important and foundational levels. It also provides disabled persons an opportunity to exercise "their right to equality of opportunity in society" (Sulmasy, 2010, p. 183). Research that directly relates to the heart of disability studies becomes shaped by the same people it affects, setting a precedent that should be considered for all research conducted in the discipline. 
Through the methods used to create materials, and through the final materials themselves, which demonstrate a rarely examined section of Canadian history and which explicitly links itself to disability studies, the Living Archives project has the potential to shape studies in disabilities. Through the scope and scale that the Living Archives project is examining, the project could become a key work in the field. Certainly, the project will at least bring to the forefront the importance of works in disability studies that are the product of the voices of vulnerable populations themselves, such as "Hear My Voice: Stories Told by Albertans with Developmental Disabilities Who Were Once Institutionalized," or the upcoming autobiography written by Leilani Muir, a sterilization survivor who was also the first person to file a successful law suit against the province of Alberta, Canada for wrongful sterilization under the Sexual Sterilization Act of Alberta. These works not only "capture the oral histories of an aging and vanishing population," (AACL, 2006, Cover) of individuals with developmental disabilities who were institutionalized before becoming meaningful community members, but can also at times provide "a healing and a renewing experience for people with disabilities themselves" (AACL, 2006, Cover). Further, such works may play a role in changing attitudes of "able-bodied people toward the disabled [...] through listening to the stories of disabled people and their families." (Childress, 2003, p. 159) Key works in disability studies must not only reflect the voice of academia, but the voices of the community as well in order to be accurate and inclusive, to avoid the errors of the past, and to create new, positive attitudes towards disability.

The Living Archives project also hopes to inspire future studies on eugenics in Western Canada and related subject matter, as a Canadian leader on issues concerning 
technology, human variation, and community, comparable to projects such as Facing History and Ourselves (http://www.facinghistory.org/) which provides such leadership on issues of race; or as the ACTUP Oral History Project (http://www.actuporalhistory.org/) provides on AIDS awareness and history. Likewise, the Living Archives hopes to provide a community with a lasting archive of the experiences of those individuals affected by eugenic laws and social policy, providing a sense of legitimacy and capturing information that might otherwise be lost from a generation now mostly in their $60 \mathrm{~s}$ and $70 \mathrm{~s}$. A collective memory might be built from these narratives, which would be relevant for modern discussions surrounding reproductive choice, disability, technology, and human variation. (Wilson, 2010, p.4) Further, the Living Archives, much like the comparable Montreal Life Stories (http://lifestoriesmontreal.ca/) project out of Concordia University focusing on the experiences of Montrealers displaced by war, genocide, and other human rights violations, wishes to provide an oral history that seeks to impart information in a respectful way to the public, without re-traumatizing survivors. Upon its completion, the Living Archives could be an integral work to the history and context of Canadian disabilities studies, for presentation, methodology, and precedent.

\section{Eugenics and Canadian Disability Studies}

The work of the Living Archives on Eugenics in Western Canada project is interesting, for it demonstrates links between the field of disability studies, and a number of other concepts including, but not limited to eugenics. Immigration studies for example, finds parallels in the history of eugenics. "The concepts of gender, race, class, and dis/ability are fundamentally intertwined," (Stubblefield, 2007, p. 162) as analysis of eugenic 
sterilization reveals. By extension, the deliverables of the Living Archives project are valuable resources to a number of different disciplines, including psychology, genetics, philosophy, and sociology, among others. This demonstrates the ways disability studies may relate and interact with other disciplines. Disability studies also become relevant to contemporary society through the exploration of transformative scientific and medical technologies, and how these advancements should be allowed or involved in our decision-making.

Further, the work of the Living Archives project provides a historic and geographic definition to disability studies that is unique in the world. The project demonstrates Canadian leadership on issues surrounding technology, human variation, and community. It is a truly Canadian perspective. The inclusive nature of the project also provides new methods and approaches to the field through the creation of "living archives," including new resources such as paper archival material, digital finding aids, curriculum development, video narratives, and in-person delivery of information (Wilson, 2010, p.7). The project demonstrates the numerous levels that can be involved with disability studies, and how they can all be linked together.

By examining the relationship of Canadian disability studies and eugenics, however, disability studies become placed within a global context. Eugenics was a movement on a global scale; the involvement of Canada helped it become "an international Eugenic Science” (Mitchell et al, 2003, p. 843). It was a movement that linked many different disciplines and studies together. Understanding the Western Canadian chapter of eugenics and disability also helps frame Canadian disability studies within an international space and context. 
Perhaps most of all, however, the Living Archives project can help emphasize the importance of inclusivity, not only in the community, but also in disability research itself. In the words of Childress (2003), such inclusion challenges "the dangerous idea" that the ability and life of a person with a disability "is necessarily [...] bad," (p. 174) or that such individuals are not worthy of participating in research and education of such sensitive topics. The project entails study alongside community partners and vulnerable people; but also, the creation and design of deliverables that are useful for them - whether this is a record of their individual history, or the creation of working materials such as a website, that is open and accessible. This creates a precedent that all disability studies research should try to meet in order to avoid becoming exclusive and recreating the same errors the discipline is attempting to study. In any case, the Living Archives project certainly has the potential to become a key work in disability studies, and provide lasting public and research content.

The Living Archives project can be contacted through their website (http://eugenicsarchive.ca), and at any time, invites interested government and community partners to contact the project and become involved. 


\section{References}

Alberta Association for Community Living (2006). Hear My Voice: Stories Told by Albertans with Developmental Disabilities Who Were Once Institutionalized. Edmonton, AB:

Alberta Association for Community Living.

ACT UP: AIDS Coalition to Unleash Power. (1988) Retrieved August 18, 2011, from http://www.actupny.org/

Childress, K. D. (2002). Genetics, Disability, and Ethics: Could Applied Technologies Lead To A New Eugenics? Journal of Women \& Religion, 20, 157-178.

Dodd, D. (2009). Canadian Historic Sites and Plaques: Heroines, Trailblazers, The Famous Five. CRM: The Journal of Heritage Stewardship, 6(2), 29-66.

Eugenic. (1989). In Oxford English Dictionary Online. Retrieved from http://www.oed.com.login.ezproxy.library.ualberta.ca/view/Entry/64958

Facing History and Ourselves: Helping Classrooms and Communities Worldwide Link the Past to Moral Choices Today. (2011) Retrieved August 17, 2011, from http://www.facinghistory.org/

Fisher, J. (2010). Eugenics in the News. Paper presented at the Inaugural Public Conference for Living Archives on Eugenics in Western Canada, Edmonton, AB.

FitzGerald, J. (2010). What Disturbs Our Blood: A Son's Quest to Redeem the Past. Toronto, ON: Random House Canada.

Galton, F. (1883). Inquiries into Human Faculty and its Development. London: Macmillan.

Grekul, J. (2008). Sterilization in Alberta, 1928 to 1972: Gender Matters. Canadian Review of Sociology, 45(4), 247-266. doi: 10.1111/j.1755-618X.2008.00014.x

Grekul, J., Krahn, A., \& Odynak, D. (2004). Sterilizing the "Feeble-minded": Eugenics in 
Alberta, Canada, 1929-1972. Journal of Historical Sociology, 17(4), 358-384. doi: 10.1111/j.1467-6443.2004.00237.x

Histoires de vie Montreal - Montreal Life Stories. (2010) Retrieved August 17, 2010, from http://lifestoriesmontreal.ca/

Mansell, D. \& Hibberd, J. (1998). "We picked the wrong one to sterilize": the role of nursingin the eugenics movement in Alberta, 1920 - 1940. International History of Nursing Journal, 3(4), 4-11.

Mitchell, D., \& Snyder, S. (2003). The Eugenic Atlantic: race, disability, and the making of an international Eugenic Science, 1800-1945. Disability \& Society, 18(7), 843-864.

O'Brien, G. V., \& Bundy, M. E. (2009). Reaching Beyond the "Moron": Eugenic Control of Secondary Disability Groups. Journal of Sociology \& Social Welfare, 36(4), 19.

Rembis, M. A. (2009). (Re)Defining disability in the 'genetic age': behavioral genetics, 'new' eugenics and the future of impairment. [Article]. Disability \& Society, 24(5), 585-597. doi: $10.1080 / 09687590903010941$

Savell, K. (2004). Sex and the Sacred: Sterilization and Bodily Integrity in English and Canadian Law. McGill Law Journal, 49(4), 1093-1141.

Selden, S. (2000). Eugenics and the social construction of merit, race and disability. Journal of Curriculum Studies, 32(2), 235-252. doi: 10.1080/002202700182736

Stubblefield, A. (2007, Spring). "Beyond the Pale": Tainted Whiteness, Cognitive Disability, and Eugenic Sterilization, Hypatia, 22(2), 162-181. Retrieved from http://login.ezproxy.library.ualberta.ca/login?url=http://search.ebscohost.com/login.aspx? direct $=$ true $\& \mathrm{db}=1 \mathrm{fh} \& \mathrm{AN}=24127104 \&$ site $=$ eds-live $\&$ scope $=$ site

Sulmasy, D. P. (2010). Dignity, Disability, Difference, and Rights. Philosophy and Medicine, 
104, 183-198.

Wendel-Hummell, C., \& Craig, C. (2009). The Lasting Legacy of Eugenics on the Right for People with Disabilities to Sexuality and Reproduction. Conference Papers -- American Sociological Association, 1, 1-24.

What Sorts of People Bloggers. (2011, August 10). Two Edmonton Fringe Plays on Eugenics and Ableism. [Web log entry]. Retrieved from http://whatsortsofpeople.wordpress.com/2011/08/10/two-edmonton-fringe-plays-oneugenics-and-ableism/

Wiener, D., Ribeiro, R., \& Warner, K. (2009). Mentalism, Disability Rights and Modern Eugenics in a 'Brave New World'. Disability \& Society, 24(5), 599-610.

Wilson, R. (2010, March) Living Archives on Eugenics in Western Canada. Retrieved from http://eugenicsarchive.ca

Workman, M. (2010, November 18). Report on the Inaugural Conference for Living Archives on Eugenics in Western Canada. [Web log entry.] Retrieved from http://whatsortsofpeople.wordpress.com/2010/11/18/report-on-the-inauguralconference-for-living-archives-on-eugenics-in-western-canada/ 